\title{
A Corpus-Based Study of the Discourse Marker "Well” and Its Pragmatic Functions in L2 Learners’ Dialogues
}

\author{
LIU Hongying \\ Shanghai Univercity for Science and Technology, Shanghai, China
}

\begin{abstract}
This paper focuses on the pragmatic function of the discourse marker "well” in conversational interaction of second language learners. Based on the corpus, we divide the pragmatic functions of "well” into four levels: content level, structural level, interpersonal level, and without level (interlanguage marker). This will help us understand the use of markers, such as "well” in interlanguage and provide references for improving the pragmatic competence of second language learners.
\end{abstract}

Keywords: discourse marker, “well”, pragmatic function, L2 spoken English

\section{Introduction}

Discourse markers (DM) are one of the indispensable means adopted by speakers to achieve successful verbal communication with others. Particularly the discourse marker "well" has obtained a massive amount of attention and has been analyzed under various theoretical framework. However, most of the research conducted on "well" concentrate on analyzing the use of native speakers but not enough attention has been given to the acquisition and actual use of non-native speakers especially L2 learners in the field of second language acquisition. Therefore, this paper makes an attempt to fill the gap by collecting data from a spoken corpus made up of L2 students' dialogues and discussion about different topics and analyzing the pragmatic function of “well” among L2 speakers.

\section{Previous Studies on "Well”}

With the foundation and development of pragmatics, many scholars in the field of linguistics at home and abroad have conducted in-depth research on discourse markers in verbal communication. Levinson (2001) pointed out in 1983 when discussing the indication function of discourse that words, such as "but", "before", and "in conclusion" only represent some kind of response and continuation relationship between subsequent discourse and previous discourse.

Many foreign scholars have divided the pragmatic functions of "well” into different categories. Quirk (1985) considered "well" as a starting point for the conversation, Schiffrin (1987) considered "well" as a response marker; and Jucker's (1993) analysis is more detailed. He divides the pragmatic function of "well" into four aspects: face relaxation, discourse segmentation, discourse filling, and delay. Based on the research results of foreign scholars, domestic scholar Ran (2003) further subdivided pragmatic functions of "well” into

LIU Hongying, master, postgraduate student, Foreign Language Institute, Shanghai Univercity for Science and Technology, Shanghai, China. 
mitigator of face-threatening acts, hesitation or delay marker, insufficiency marker and repair marker. These studies not only help us understand the discourse function of "well", but also pave the way for us to study the use of pragmatic markers in L2 learners. This paper conducts a corpus and data-driven study on the actual use of "well” in a learners' spoken English corpus and tries to make a classification based on former study and in particular on the actual data collected in the true speaking context. Furthermore, this paper aims to investigate the hypothesis that some pragmatic functions used in the discourse made by L2 learners bear some patterns and can be categorized into different levels, thus reflecting the pragmatic competence of L2 learners to some extent.

\section{Data}

The corpus employed in this research is MSECCL-SEM (Liu, 2013), short for Multimodal Spoken English Corpus of Chinese Learners-Science \& Engineering Majors, including transcribed video of 150 oral group discussions with a total of 85,540 words. Four hundred and forty-two participants from five different universities of science and engineering in China covering key universities and local universities were asked to make conversations in groups. The corpus contains dialogues of groups with two to four people each. Teachers provide alternative topics, and students choose the topic and have a six-minute-long discussion. All spoken transcribed corpus texts are marked with the speaker's status, gender, major, and various non-verbal information.

The discourse marker "well" will be searched using Wordsmith 6.0 to get the frequency count and to locate it in the conversations made by the students. After the search, "well" that are not used as discourse marker will be picked out and deleted.

\section{Results and Discussion}

In the corpus, "well” appears 129 times in total, of which 66 are content words and the rest are discourse markers. In this research, two steps are taken to make the categorization of the pragmatic function of "well". First, all the discourse marker "well" found in the corpus is located in the original texts and observed by the researcher. Then, the categorization system created by other researchers serve as input and reference in this paper. Based on relevance theory, Jucker (1993) pointed out that the discourse marker "well" has the following four pragmatic functions: face threat mitigation, discourse segmentation, shortage marker, and delay language. Ran Yongping (2003) believed that the discourse marker "well" has the following four main pragmatic functions: mitigator of face-threatening acts, hesitation or delay marker, insufficiency marker, and repair marker. Based on their former findings, we divided the grammatical function of "well" into four categories (shown in Table 1).

Table 1

Overview of the Function "Well"

\begin{tabular}{lll}
\hline Level & Category & Short explanation of the function \\
\hline Content level & CRE & Correcting and rephrasing expression \\
& LRE & Looking for the right expression \\
Structural level & SEC & Starting and ending a conversation \\
& TT & Turn-taking \\
Interpersonal level & DCP & Delaying the conversation for preparation \\
Without level & MFTA & Mitigating face threatening acts \\
\hline
\end{tabular}


As Table 1 shows, "well” works at three levels: local, structural, and interpersonal. The local level refers to the situation in which the speaker makes a correction or a different expression when speaking, or looking for a suitable word or phrases to express himself. "Well" on the structural level has the function of initiating a conversation, turn-taking, and delay the conversation for some while to look for suitable expressions. The function on the interpersonal level mainly focuses on the theory of Brown and Levinson's model of face-saving politeness. Since the research participants in this research are L2 learners, another issue has to be considered for L2 learners may use discourse markers, like "well”, not for some specific reasons, but because of lack of language proficiency.

\section{Content Level}

CRE: Correcting and rephrasing expression. Also mentioned by Svartvik (1980) and Schiffrin (1987), this function means that in verbal communication, speakers sometimes need to correct previous information. As a linguistic tool, "well" has the function of editing marker. A typical example is Example 1. The two speakers were talking about how to treat their parents when they are old. Before this speaking turn, Speaker 1 (sp1) said that it is important to let our parents feel the warmth of the family and have accompany of children. He implied that he was still very young and that is the reason why he has not got any children. So, the Speaker 2 (sp2) asked him if he will have any children. He made a correction from my parents to my parents' health to make clear what he meant.

Example 1:

$<$ sp2> You will have children. $<$ sp2>

$<$ sp1> Yeah, my, I will have a children. Then I will make them to stay with my parents. En...I think it's not just good to my parents, well my parents' health...

LRE: Looking for the right expression. Sometimes people cannot find the right words to express themselves when they are speaking. So, sometimes people stop in the middle of a conversation to think about which word to use. This phenomenon is more common for L2 learners. Since English is not the native language of students, they may know what they are going to say but fail to find corresponding English expressions. The LRE category refers to looking for the right expression of a word or a phrase in the communicating process. And "well" functioning in this condition is often accompanied by fillers, like uh, en, and so on (see Example 2).

Example 2:

$<$ sp2> Er...but why, why do you want to, study abroad? $</$ sp2 $>$

$<$ sp3> En... it’s said that the foreigner are en.. well...kindly. En...when I go(er) abroad to study, I can make many friends with them.

\section{Structural Level}

SEC: Starting and ending a conversation. In communication, the speaker will use "well" to remind the listener that the topic is about to appear, change, or end. The speaker uses the discourse marker "well" to introduce the topic and start the conversation. For example:

Example 3:

$<$ sp1 $>$ Well, hi guys, how's the whether like outside? </sp1>

$<$ sp2> It's raining and winding. $</$ sp2 $>$

In Example 3, well is used to start the conversation. In this conversation, "well” is at the beginning of a conversation, meaning that the speaker wants to get attention and show that he or she is ready to start a 
conversation. "Well", on the other hand, can also mean the end of a speaking round. In this Example 4, "well" appears at the end of the conversation to indicate the conclusion and the end of the conversation. In Example 4, after discussing whether to study abroad, Speaker 2 thanks Speaker 1 for his opinion. They think they have talked about enough, so Speaker 1 says "well” and ends the conversation.

Example 4:

$<$ sp2> Maybe I don't want to go out en...thank you for your advice. Maybe I told you that I want to go. $</$ sp2 $>$

$<$ sp1 $>$ Well, that's all. $</$ sp1 $>$

$<$ sp2 $>$ Thank you. $<$ sp2 $>$

TT: Turn-taking. In a discourse, sentences are related to sentences, paragraphs to paragraphs, and there are semantic or logical relations between them. The discourse marker "well" is one of the link words, which can be used to indicate that the speaker continues to discuss the topic or answers the questions of the other speaker. At this time, it does not have any semantic meaning, but only reflects the speaker's pragmatic consciousness.

Example 5:

$<$ sp2 $>$ Yeah. And and that's why I can't do well in the exam. $<$ /sp2 $>$

$<$ sp1 > Maybe. Well, I have a class to attend later. It's time to go, I think. $</$ sp1 $>$

Here in Example 5, the two speakers are discussing how to improve the quality of education in Chinese universities. Before the round, they said China's exam system should be improved. When the first speaker said he often gets bad grades on tests. The second speaker remembered that he had a course and had to leave immediately, so the second speaker used "well" here to change the talking topic to the fact that he had to leave.

DCP: Delaying the conversation for preparation. In verbal communication, speakers sometimes use "well" as a delay marker to avoid too long pauses, indicating that the information the speaker wants to provide has not been decided or that the speaker is unwilling to give up the turn. In addition, the use of thedelaying marker "well" can also indicate that the speaker is hesitating for some reason.

Example 6:

$<$ sp2> No, I don't think so, because money couldn't er...buy any er...buy everything. </sp2>

$<$ sp1 $>$ Well, we...er... I just, I just, I just say buy something to er...certain dis, extent.

Just like Example 6, in the process of language use, the speaker is not always able to speak continuously. In this process of thinking, the discourse marker "well" may be blurted out to avoid long pauses and indicate that the information provided by the other party is not completed. So, "well" now acts as gap-filler to fill the blank.

\section{Interpersonal Level}

MFTA: Mitigating face threatening acts. In verbal communication, the speaker and the listener need to make efforts to maintain harmonious interpersonal relations and politeness. According to Brown and Levinson (1987), many speech acts can threaten the public face. Communicators need to adopt some strategies to mitigate the threat of speech behavior to face. The discourse marker "well" is a language strategy that can be used as a face threat mitigating language. Sometimes the views or opinions of both parties in communication will conflict or the speaker's request is refused by the listener. When the above type of situation occurs, the face of the speaker or listener will be threatened, while "well"can reduce the threat of face of the speech act. 
Example 7:

$<$ sp3> Yes. En...you learn many things together like(er) playing games, watching films and(er) only those people who er...share the same life value they can er...overcome life differe difficulties. $</$ sp3>

$<$ sp1 $>$ Well, in my opinion, I prefer to make make people make friends with people who are different from me.

Example 7 presents the case that the two speakers disagree about what kind of friends to have. Speaker 3 thinks people should get along with people who are similar to themselves, while Speaker 1 thinks making friends with different personalities is good for his growth. It can be very blunt to state your different point of view directly. Therefore, in this dialogue, Speaker 1 uses "well” to introduce his or her different opinions to soften the tone and protect the other person's positive face.

IM: Interlanguage marker due to low proficiency. Another factor to be considered in this study is the participants of this study. Besides the pragmatic functions mentioned above, it is found that some of the discourse markers are frequently used due to low language proficiency of the L2 learners. As can be seen from Example 8, "well” is also surrounded by lots of fillers, like en and er, representing the case in which the student cannot express fluently in English due to low language proficiency. He use the word "well” to fill in pauses and gaps. This is also a communicative strategy that second language learners often use in their daily oral English where they use meaningless words to maintain their conversational fluency.

Example 8:

...En...also en...weller...the internet also can also en...er...prove en... </sp1>

\section{Conclusion}

At the beginning of this paper, the author proposes the hypothesis that the use of "well” in daily oral communication of second language learners has certain observable rules and can be classified into different functions. In this paper, word Smith tools 6.0 is used to search "well” in the corpus MSECCL-SEM. Researchers locate and observe its context of "well” as a discourse marker and analyze and categorize its functions. This paper only makes a little discussion on the classification of "well” used by second language learners without revealing the underlying reasons. Subsequently, questionnaires can be conducted on the second language learners participating in the study to explore their awareness of using discourse markers. In addition, the differences between Chinese English learners and native speakers can be concluded by comparing the parallel corpus of native speakers in the future.

\section{References}

Brown, P., \& Levinson, S. (1978). Universals in language usage: Politeness phenomena. In E. N. Goody (Ed.), Questions and politeness: Strategies in social interaction (pp. 56-289). Cambridge: Cambridge University Press.

Jucker, A. H. (1993). The discourse marker well: A relevant theoretical account. Journal of Pragmatics, (5), 435-452.

Levinson, S. C. (2001). Pragmatics. Beijing: Foreign Language Teaching and Research Press.

Liu, Q. (2013). Corpus-based integration of oral English teaching and assessment for Chinese science and engineering college students. Shanghai: Fudan University Press.

Quirk, R. (1985). A comprehensive grammar of the english language. London: Longman.

Ran, Y. P. (2003). Pragmatic function of discourse marker well. Foreign Language, (3), 58-63.

Schiffrin, D. (1987). Discourse markers. Cambridge:Cambridge University Press.

Svartvik, J. (1980). Well in conversation. In S. Greenbaum, G. Leech, and J. Svartvik (Eds.), Studies in English linguistics for randolph quirk (pp. 167-177). Longman, London. 